\title{
Tuning the excited state properties of [2.2]paracyclophane-based antennas to ensure efficient sensitization of lanthanide ions or singlet oxygen generation.
}

\author{
Shiqi Wu, ${ }^{\mathfrak{f}, \dot{ }}$ Laura Abad Galán, ${ }^{\mathfrak{f}, \dagger}, *$ Margaux Roux, ${ }^{\dagger}$ François Riobé, ${ }^{\dagger}$ Boris Le Guennic, ${ }^{\neq}$Yannick \\ Guyot, ${ }^{+}$Tangui Le Bahers, ${ }^{\dagger}$ Laurent Micouin, ${ }^{\star}$ Olivier Maury, ${ }^{\dagger, *}$ Erica Benedetti ${ }^{\ddagger}{ }^{*}$. \\ $£$ Both authors contribute equally to the work \\ † Univ Lyon, ENS de Lyon, université Claude Bernard Lyon 1, CNRS UMR 5182, Laboratoire de Chimie, F-69342 Lyon, \\ France. E-mail: laura.abad-galan@ens-lyon.fr, olivier.maury@ens-lyon.fr \\ $\$$ Univ Paris, Laboratoire de Chimie et Biochimie Pharmacologiques et Toxicologiques - UMR8601 CNRS, 45 rue des Saints \\ Pères, 75006 Paris, France. E-mail: erica.benedetti@u-paris.fr \\ \# Univ Rennes, CNRS, ISCR (Institut des Sciences Chimiques de Rennes) - UMR 6226, F-35000 Rennes, France. \\ + Univ Lyon, Institut Lumière Matière, UMR 5306 CNRS-Université Claude Bernard Lyon 1, 10 rue Ada Byron, 69622 \\ Villeurbanne Cedex, France.
}

Supporting Information Placeholder

ABSTRACT The multi-step synthesis of original antennas incorporating substituted [2.2]paracyclophane (pCp) moieties in the $\pi$-conjugated skeleton is described. These antennas, functionalized with electron an donor alkoxy fragment $\left(\mathbf{A}^{\mathbf{1}}\right)$ or with a fused coumarin derivative $\left(\mathbf{A}^{2}\right)$ are incorporated in a triazacyclonane macrocyclic ligand $\mathbf{L}^{\mathbf{1}}$ or $\mathbf{L}^{2}$, respectively for the design of $\mathrm{Eu}(\mathrm{III}), \mathrm{Yb}(\mathrm{III})$ and $\mathrm{Gd}(\mathrm{III})$ complexes. A combined photophysical/theoretical study reveals that $\mathbf{A}^{\mathbf{1}}$ presents a charge transfer character via the through-space paracyclophane conjugation, whereas $\mathbf{A}^{2}$ presents only local excited states centered on the coumarin-paracyclophane moiety, strongly favoring triplet state population via intersystem crossing. The resulting complexes $\mathrm{Eu} \mathbf{L}^{1}$ and $\mathrm{YbL}^{2}$ are fully emissive in the red and near infrared, respectively whereas the $\mathrm{Gd}_{\mathbf{L}}{ }^{2}$ complex acts as photosensitizer for the generation of singlet oxygen.

\section{Introduction}

Since the discovery of the "red phosphor", i.e. the red emission of europium(III) diluted in solid matrix $\left(\mathrm{Eu}_{2} \mathrm{Y}_{2} \mathrm{O}_{3}\right)$ by George Urbain in the early 1900's, the luminescence of the f-elements has always held a real fascination for the scientific community. ${ }^{1}$ This one-century old enthusiasm is still justified by the very particular photophysical properties of these elements which show very narrow emission lines originated by the forbidden intra-atomic f-f transitions spread from the visible to the near infra-red with long excited state lifetimes in the $\mu$ s-to-ms range. ${ }^{1-2}$ These characteristics have been widely investigated in many application areas ranging from material sciences for lightning, ${ }^{3}$ multicolor barcoding ${ }^{4}$ or displays, to biology for imaging ${ }^{5-8}$ or immuno-assay. ${ }^{9-11}$ From a more fundamental point of view, the high resolution luminescence, characteristic of the symmetry of the coordination sphere (crystal-field splitting), can be correlated with other related properties like magnetism for instance. ${ }^{12-14}$ However, due to the forbidden character of $\mathrm{f}-\mathrm{f}$ transitions, the extinction coefficients are generally very low (1$10 \mathrm{~L} . \mathrm{mol}^{-1} \cdot \mathrm{cm}^{-1}$ ) precluding direct excitation in these transitions, in particular for molecular compounds diluted in solution. To overcome this drawback, Weissman discovered in the early 40's an indirect sensitization mechanism mediated by a coordinated ligand able to absorb efficiently light and transfer the energy to the emitting metal ion. ${ }^{15}$

This intramolecular energy transfer is referred to as the "antenna effect", following Lehn and Sabbatini studies on the tris-bipyridine cryptate europium complex. ${ }^{16}$ Several sensitization photophysical mechanisms have been proposed involving either the triplet excited state of the antenna or a direct energy transfer from the singlet one. ${ }^{17}$ The optimization of the antenna effect for a given lanthanide ion consists of simultaneously optimizing the sensitization process $(\phi)$ and the absorption at the wavelength of interest $(\varepsilon)$, leading in fine to the highest possible brightness $\mathrm{B}^{(1)}=\varepsilon . \phi$. This quest strongly stimulates the researchers' creativity as illustrated by the exceptional variety of polydentate or macrocyclic ligands published each year, where large brightness has been achieved using very different structures. As selected examples, record brightness has been obtained for (i) Eu(III) using macrocyclic triazacyclononane platform functionalized by a $\pi$-conjugated chromophore, ${ }^{18}$ (ii) $\mathrm{Tb}$ (III) thanks to a cryptate ligand ${ }^{19-20}$ and (iii) $\mathrm{Yb}$ (III) using a sandwich complex between a porphyrin and a Kläui's tripodal ligand. ${ }^{21}$ A large variety of chromophores have been tested as antenna among which polyaromatic dyes (anthracene, pyrene), ${ }^{22-23}$ xanthene $^{24}$ and coumarin 
derivatives, ${ }^{25-26} \pi$-conjugated chromophores (Michler ketone, ${ }^{27}$ tetra-thiafulavalene, ${ }^{28}$ dipolar dyes ${ }^{29-30}$ ), coordination or organometallic complexes, ${ }^{31-32}$ porphyrins, ${ }^{21}$ dithienylethene, ${ }^{33}$ murexide, ${ }^{34-35}$ bodipy dyes ${ }^{36-37}$ etc...

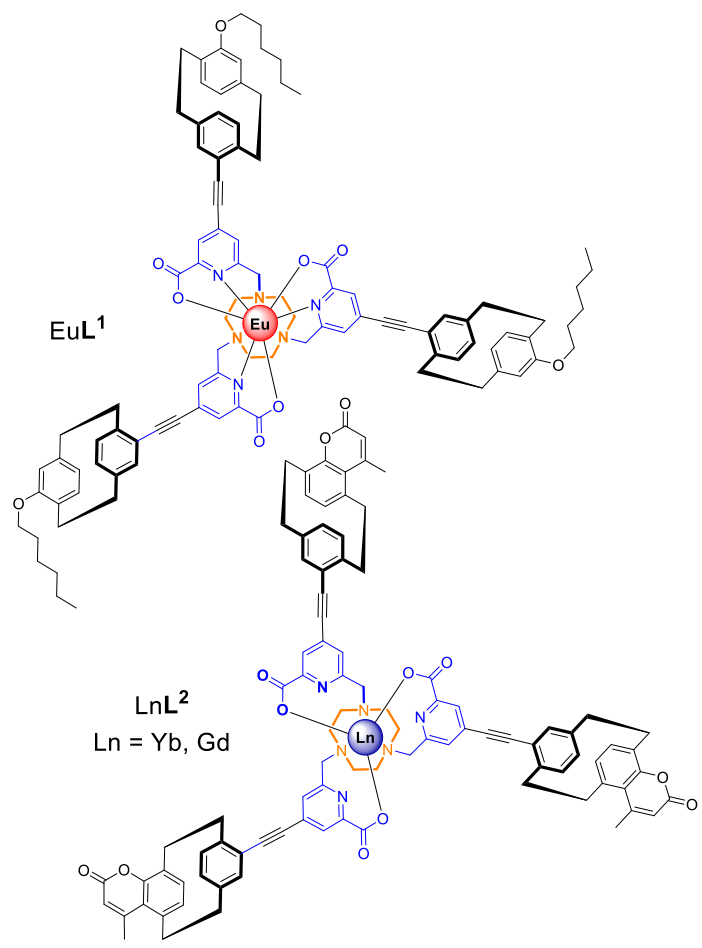

Figure 1. Structure of lanthanide complexes featuring the $\mathrm{pCp}$ based picolinate antennas.

Herein, we report the use of [2.2]-paracyclophane (pCp) chromophore for the design of tunable antennas. $\mathrm{pCp}$ is a sandwich-like molecule that features two phenyl rings linked together by two ethylene bridges at their para position. ${ }^{38-39}$ The strong $\pi-\pi$ electronic interactions occurring between the two aromatic "decks" of pCp ensure an efficient "through-space" delocalization that can be employed to develop original $\pi$ conjugated chromophores as illustrated for instance by Bazan's work in nonlinear optics. ${ }^{40-41}$ More recently, some of $\mathrm{us}^{42}$ and others researchers ${ }^{43}$ have taken advantage of the intrinsic planar chirality of these scaffolds ${ }^{44}$ to design chiral dyes for circularly polarized luminescence applications. Surprisingly, the literature briefly reports only one example of a $\beta$-diketonate ligand substituted by a pCp moity for the sensitization of $\mathrm{Eu}(\mathrm{III})$ luminescence. ${ }^{45}$ In the course of our ongoing study on the design of donor- $\pi$-conjugated picolinate charge transfer antennas to optimize the brightness of various lanthanide ions, ${ }^{46-48}$ we have focused our attention on the synthesis of new antennas incorporating $\mathrm{pCp}$ chromophores substituted by either an alkoxy donor group or a fused coumarin moiety. With the two pCp-based antennas in hand, the corresponding triazacyclononane (TACN) macrocyclic ligands have been prepared and employed to access Eu(III), Yb(III) and Gd(III) complexes (Figure 1). The combined spectroscopic/theoretical study described in the next sections allowed us to fully rationalize the photophysics of the $\mathrm{pCp}$-based chromophores, as well as their related antennas and Ln complexes. It appears that the alkoxy substituted antenna is highly efficient for $\mathrm{Eu}(\mathrm{III})$ sensitization, whereas the coumarin-based antenna is better suited for sensitizing $\mathrm{Yb}(\mathrm{III})$, or photoactivating singlet oxygen when associated with $\mathrm{Gd}(\mathrm{III})$.

\section{Results and discussions}

Synthesis. The synthesis of the desired Ln(III) complexes began with the preparation of the two antenna chromophores containing the pCp conjugated scaffold. The first compound, substituted with an electro-donating OHex group (( \pm )-5), was prepared in four steps starting from commercially available 4,16-dibromo[2.2]paracyclophane 1 (Scheme 1). A brominelithium exchange, followed by the addition of trimethylborate, and in situ oxidation of the resulting boronic ester with $\mathrm{H}_{2} \mathrm{O}_{2}$ and $\mathrm{NaOH}$ readily afforded phenol $( \pm)-2$ in $85 \%$ yield. ${ }^{49-50}$

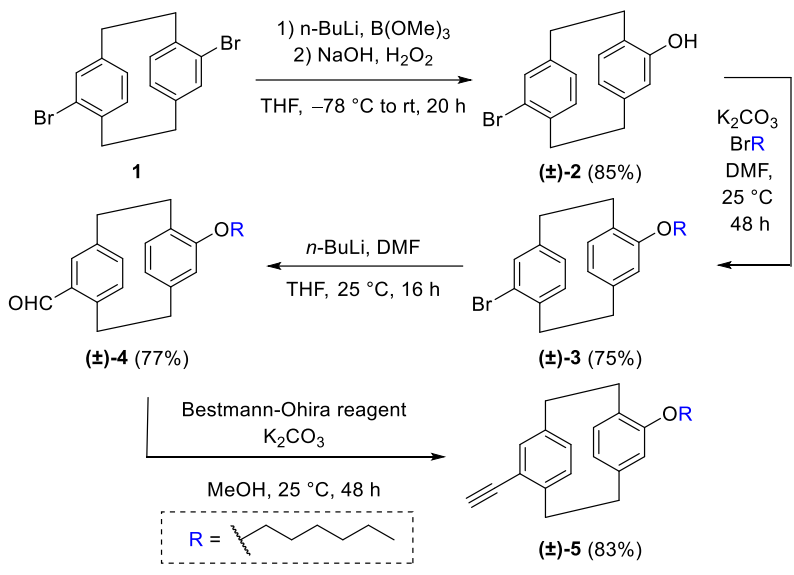

Scheme 1. Synthesis of pCp-based chromophore ( \pm )-5.

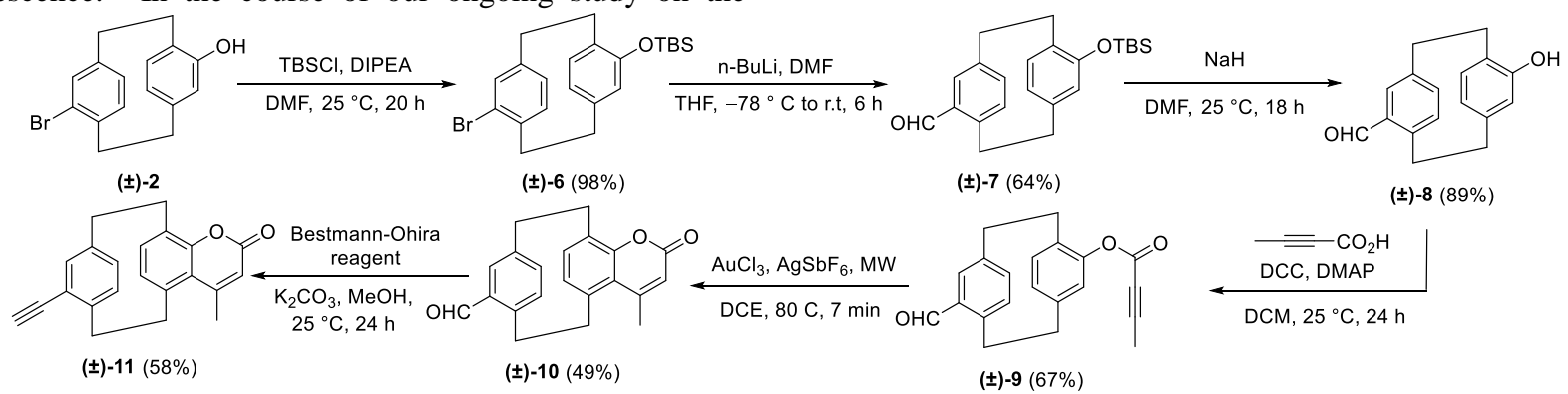

Scheme 2. Synthesis of coumarin fused pCp-based chromophore ( $( \pm)-\mathbf{1 1}$. 

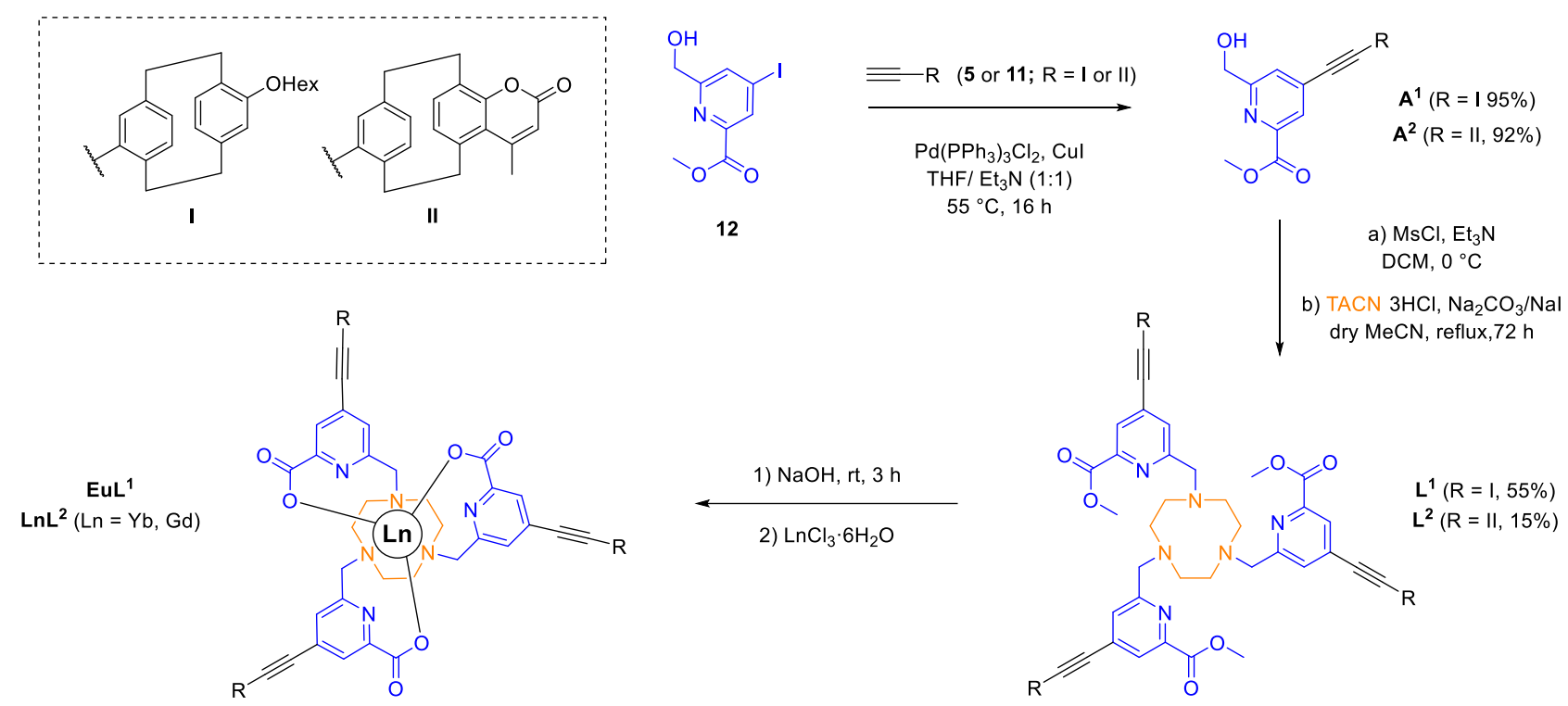

Scheme 3. Synthesis of antenna chromophores $A^{\mathbf{1 , 2}}$, macrocyclic ligands $\mathbf{L}^{\mathbf{1 , 2}}$ and related lanthanide complexes.

Note that dissymetrically substituted pCp such as $\mathbf{2}$ are chiral molecules (planar chirality) and ( \pm ) indicates the formation of the racemic mixture. Etherification of $( \pm)-2$ with 1bromohexane in the presence of $\mathrm{K}_{2} \mathrm{CO}_{3}$ generated product $( \pm)$ 3 in $75 \%$ yield. A second bromine-lithium exchange and subsequent formylation with DMF led to the formation of aldehyde $( \pm)-4$ in $77 \%$ yield. Treatment of this compound with Bestmann-Ohira reagent ${ }^{50}$ finally allowed us to isolate alkyne $( \pm)-5$ in $83 \%$ yield. The second pCp-based chromophore incorporates a fused coumarin moiety. It was synthesized in six steps starting from phenol $( \pm)-2$ (Scheme 2 ). The reactive hydroxyl group of this molecule was first protected as silyl ether through a reaction with tert-butyldimethylsilyl chloride (TBSCl) in the presence of a base (DIPEA). The resulting compound ( \pm )-6 was successfully engaged in a bromine-lithium exchange and formylation with DMF to provide product $( \pm)-7$ in $64 \%$ yield. After cleavage of the TBS protecting group with $\mathrm{NaH}$, phenol $( \pm)-8$ was submitted to esterification with 2butynoic acid, N,N'-dicyclohexylcarbodiimide (DCC), and 4dimethylaminopyridine (DMAP) to afford ester $( \pm)-9$ in $67 \%$ yield. This $\alpha, \beta$-unsaturated derivative underwent a gold- and silver-catalyzed intramolecular cyclization, under microwave irradiation, to generate the desired coumarin product $( \pm)-\mathbf{1 0}$ in $58 \%$ yield. $^{42}$ The aldehyde function of this compound was finally converted into a triple bond via Seyferth-Gilbert homologation. ${ }^{50}$

Starting from the pCp-based chromophores $( \pm)-\mathbf{5}$ and ( \pm )-11, antennas $\mathbf{A}^{\mathbf{1}}$ and $\mathbf{A}^{\mathbf{2}}$ were prepared through Sonogashira crosscoupling reactions with iodo-picolinic ester $\mathbf{1 2}$ as previously exemplified in our group (Scheme 3). ${ }^{47}$ Compounds $\mathbf{A}^{\mathbf{1}}$ and $\mathbf{A}^{\mathbf{2}}$ were finally linked to TACN after a mesylation step, leading to the formation of the ligands $\mathbf{L}^{\mathbf{1}}$ and $\mathbf{L}^{\mathbf{2}}$ after purification by column chromatography. The antennas and the corresponding ligands were all obtained as mixtures of enantiomers and diastereoisomers, respectively. All the synthetized compounds have been fully characterized by ${ }^{1} \mathrm{H}$ and ${ }^{13} \mathrm{C}$ NMR spectroscopy as well as mass spectrometry (see SI for details). The complexation with the desired lanthanide ion was finally achieved by in situ saponification and addition of the hydrated lanthanide chloride salt at $\mathrm{pH}=6$ in a $\mathrm{THF} / \mathrm{H}_{2} \mathrm{O}$ mixture (Scheme 3). The final complexes $\mathrm{EuL}^{\mathbf{1}}, \mathrm{YbL}_{\mathbf{2}} \mathbf{2}, \mathrm{GdL}^{2}$ were obtained in quantitative yields after extraction in dichloromethane (DCM).

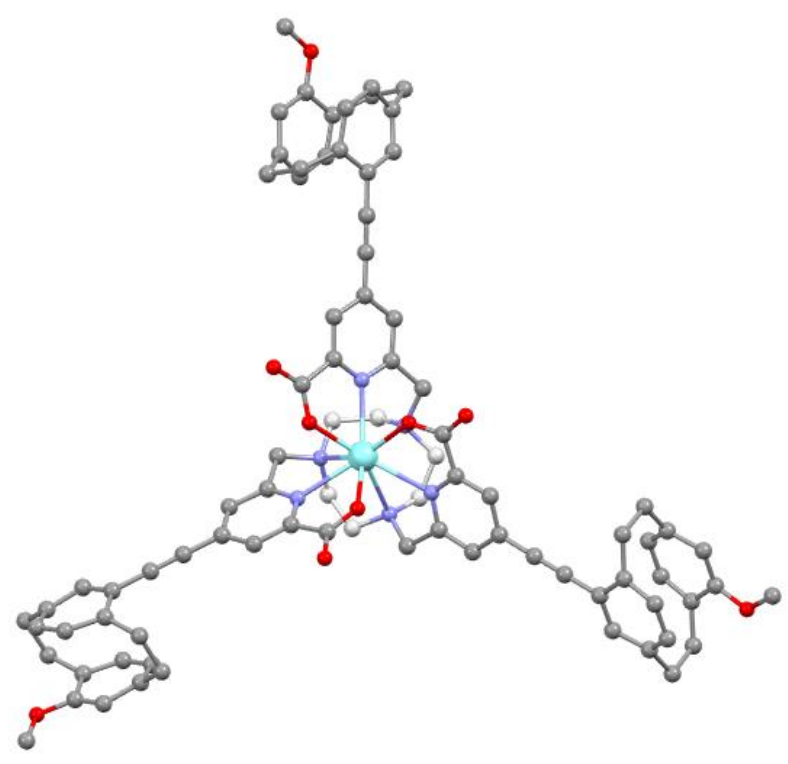

Figure 2. DFT optimized [YL' ${ }^{1}$ ] structure. Hydrogen atoms are omitted for clarity, $\mathrm{C}$ are represented in gray, $\mathrm{O}$ in red, $\mathrm{N}$ in blue and $\mathrm{Y}$ in aqua blue.

In our hand, it was impossible to grow crystal suitable for X-ray diffraction certainly due to the large number of isomers present 
arising from both the racemic $\mathrm{pCps}\left(\mathrm{R}_{\mathrm{p}}\right.$ or $\mathrm{S}_{\mathrm{p}}$ configurations), and the wrapping of the picolinate around the metal with $\Lambda$ or $\Delta$ stereochemistry. Therefore, a computed optimized structure using $\mathrm{Y}$ (III) as the metallic center and simplified $\mathbf{L}^{\mathbf{1}}$ ' ligands featuring -OMe instead of -OHex end-groups, was performed by DFT as previously done for similar complexes. ${ }^{47}$ The resulting optimized structure, presented in Figure 2, highlights that despite the $\mathrm{pCp}$-based chromophore's size, steric hindrance does not seem to interfere with the expected $D_{3 h}$ complex symmetry. Investigation of some other possible isomers reveals that the stabilization energy is almost constant (within \pm 1 kcal.mol ${ }^{-1}$ ) confirming the racemic character of the prepared complexes.

Photophysical and theoretical study of the pCp-based chromophores and antennas. The photophysical properties of the pCp chromophores ( \pm -5 and ( \pm -11, and the corresponding antennas $\mathbf{A}^{\mathbf{1}}$ and $\mathbf{A}^{\mathbf{2}}$ were thoroughly investigated. Absorption, emission spectra (fluorescence and phosphorescence), fluorescence quantum yields, as well as singlet oxygen generation were measured for all derivatives in different organic solvents (toluene, dichloromethane, and acetonitrile). The main photophysical data recorded in dichloromethane at room temperature and $77 \mathrm{~K}$ are compiled in Table 1.

The experimental absorption and emission spectra of the chromophore $( \pm)-5$ are similar to those of the unsubstituted commercially available pCp in the same solvent. ${ }^{51}$ Indeed, a strong absorption band with a maximum at $250 \mathrm{~nm}$ and two weak absorption bands centered around 300 and $313 \mathrm{~nm}$ were observed together with an emission maximum at $367 \mathrm{~nm}$ (Figure S1). This derivative presents a subtle bathochromic shift for both absorption and emission in comparison to the unsubstituted $\mathrm{pCp}$, which could be explained by the electrondonating effect from the -OHex fragment. In sharp contrast, the main absorption band of $\mathbf{A}^{\mathbf{1}}$ located around $315 \mathrm{~nm}$ is strongly enhanced with an extinction coefficient 20 times higher than that observed for ( \pm )-5 (Figure 3 ). In addition, the emission spectrum of this antenna shows a broad structureless band centered at $497 \mathrm{~nm}$. Compared to ( \pm )-5, $\mathbf{A}^{\mathbf{1}}$ therefore displays a considerably red-shifted luminescence $(+130 \mathrm{~nm})$ and a strongly increased Stokes shift $\left(11325 \mathrm{~cm}^{-1}\right.$ vs $4700 \mathrm{~cm}^{-1}$ for ( \pm )5, Figure S2). Interestingly, a significant positive solvatochromism was observed for $\mathbf{A}^{\mathbf{1}}$ when moving from toluene to acetonitrile. This behavior is more pronounced in emission, as confirmed from the positive linear tendency of the Lippert-Mataga plot (Figure S3). All these features are consistent with the assignment of this transition to a throughspace charge transfer (CT) transition from the electron-donating -OHex fragment to the picolinate group acting as the electronwithdrawing group via the $\mathrm{pCp}$ conjugated skeleton (vide infra). The maximum emission intensity corresponds to the relaxed $\mathrm{CT}$ excited state, $\mathrm{E}\left(\mathrm{CT}^{*}\right)=20100 \mathrm{~cm}^{-1}$. In order, to complete the simplified Jablonsky energy diagram, the localization of triplet excited state was investigated using low temperature emission spectroscopy. The emission spectra of $( \pm)-5$ and $\mathbf{A}^{\mathbf{1}}$ were recorded in frozen DCM solutions at $77 \mathrm{~K}$ (Figure 3$)$ with and without a delay $(0.1 \mathrm{~ms})$ to suppress short lived fluorescence. In the case of $( \pm$ )-5 (Figure S1), the $77 \mathrm{~K}$ fluorescence is comparable to the RT one, and is accompanied by an intense phosphorescence band centered at $494 \mathrm{~nm}$. For $\mathbf{A}^{\mathbf{1}}, 77 \mathrm{~K}$ fluorescence is strongly blue shifted compared to the RT signal and now correspond to that of $( \pm)-5$. This behavior can be rationalized by the fact that at low temperatures, in the glassy solid matrix the increased medium viscosity associated with the suppression of molecular motions avoid solvent reorganization around the excited chromophore resulting in the increase of the CT energy level. ${ }^{52,53}$ Application of a delay, allows to observe a less intense phosphorescence centered at $515 \mathrm{~nm}$ from which we could assigned the lowest triplet state emission at $20000 \mathrm{~cm}^{-1}$.

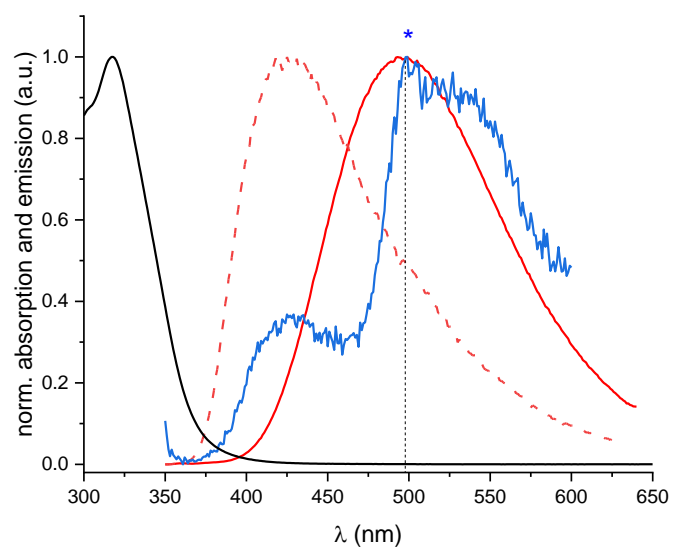

Figure 3. Normalized absorption (black bold) and emission (red bold) of $\mathbf{A}^{\mathbf{1}}$ in dichloromethane at room temperature, $77 \mathrm{~K}$ emission (red dashed) and phosphorescence spectrum (blue) after application of a $0.1 \mathrm{~ms}$ delay.

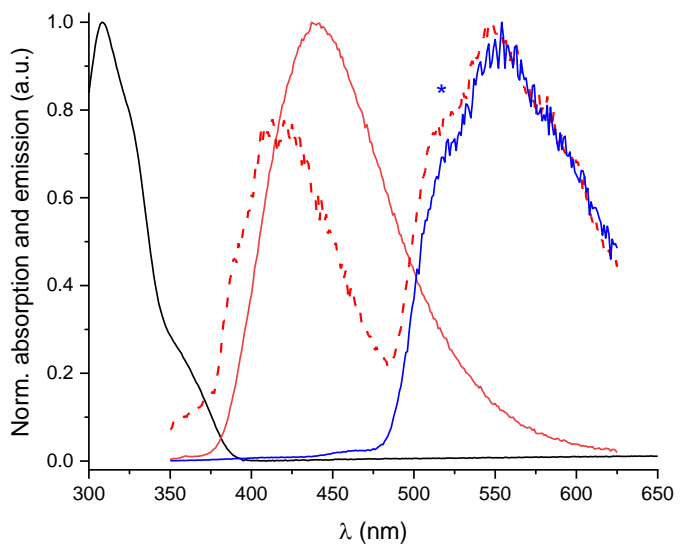

Figure 4. Normalized absorption (black) and emission (red) of $\mathbf{A}^{\mathbf{2}}$ in dichloromethane at room temperature, $77 \mathrm{~K}$ emission (red dashed) and phosphorescence spectrum (blue) after application of a 0.1 ms delay. 
Table 1. Main photophysical properties of the $\mathrm{pCp}$ chromophores and corresponding antennas in diluted DCM at RT and 77K.

\begin{tabular}{|c|c|c|c|c|c|c|c|c|}
\hline compounds & & $\begin{array}{l}\lambda_{\mathrm{abs}} \\
(\mathrm{nm})\end{array}$ & $\begin{array}{c}\varepsilon \\
\left(\mathrm{L} . \mathrm{mol}^{-1} \cdot \mathrm{cm}^{-1}\right)\end{array}$ & $\begin{array}{c}\lambda_{\mathrm{em}} \\
(\mathrm{nm})\end{array}$ & $\begin{array}{l}\text { Stokes shift } \\
\qquad\left(\mathrm{cm}^{-1}\right)\end{array}$ & $\begin{array}{l}\mathrm{E}\left(\mathrm{T}_{1}\right)^{\mathrm{a}} \\
\left(\mathrm{cm}^{-1}\right)\end{array}$ & $\Phi_{\mathrm{f}}^{\mathrm{b}}$ & $\Phi_{\Delta}{ }^{\mathrm{c}}$ \\
\hline \multirow{2}{*}{$( \pm)-5$} & RT & 313 & 1,000 & 367 & 4,701 & - & 0.02 & \multirow{4}{*}{-} \\
\hline & $77 \mathrm{~K}$ & - & - & 364 & - & 21,600 & - & \\
\hline \multirow{2}{*}{$\mathbf{A}^{1}$} & RT & 317 & 17,700 & 497 & 11,325 & - & 0.09 & \\
\hline & $77 \mathrm{~K}$ & - & - & 365 & - & 20,000 & - & \\
\hline \multirow[t]{2}{*}{$( \pm)-11$} & RT & 326 & 9,500 & 430 & 9,211 & - & 0.01 & 0.70 \\
\hline & $77 \mathrm{~K}$ & - & - & 420 & - & 19,600 & & \\
\hline \multirow{2}{*}{$\mathbf{A}^{2}$} & RT & 322 & 25,750 & 425 & 7,720 & - & 0.02 & 0.60 \\
\hline & $77 \mathrm{~K}$ & - & - & 410 & - & 19,500 & & \\
\hline
\end{tabular}

a. Assigned to the first deconvoluted band of the phosphorescence spectrum after a 0.1 ms delay as marked in the corresponding figures. b. Measured by comparative method using coumarin-153 ( $\Phi_{\mathrm{f}}=0.45$ in methanol) as standard. c. Measured by comparative method using phenalenone as standard $\left(\Phi_{\Delta}=0.98\right.$ in dichloromethane) ${ }^{54}$

The same study performed on the fused coumarin derivatives $( \pm)-\mathbf{1 1}$ and the corresponding antenna $\mathbf{A}^{\mathbf{2}}$ reveals different behaviors. In both cases, the photophysical properties are governed by the coumarin-pCp chromophore, with the characteristic $\pi \rightarrow \pi^{*}$ absorption band centered at ca. $325 \mathrm{~nm}$ and the localized emission band at ca. $430 \mathrm{~nm}$ (Figures 4 and S4). Interestingly, no solvatochromism was observed for any derivative (Figures S5), highlighting the localized nature of the states involved in both the absorption and emission processes. When the emission studies were performed at low temperature, a more intense broad phosphorescence band appeared with a maximum at ca. $550 \mathrm{~nm}$ whose character was confirmed by its persistence when a $0.1 \mathrm{~ms}$ delay was applied (Figure 4). These measurements allow the assignment of the lowest energy triplet state at $19500 \mathrm{~cm}^{-1}$, significantly stabilized compared to the first -OHex series. The intense phosphorescence band observed at low temperature combined with the low emission quantum yields for all derivatives $(<0.02)$ suggests an easier intersystem crossing to populate the triplet state for the fused coumarin derivatives. These observations prompted us to study a possible generation of singlet oxygen. As expected, the characteristic phosphorescence band of ${ }^{1} \mathrm{O}_{2}$ at $1270 \mathrm{~nm}$ was detected at room temperature upon excitation of the coumarin containing compounds. Contrarily, the -OHex derivatives ( \pm )-5 and $\mathbf{A}^{\mathbf{1}}$ failed to activate molecular oxygen. The efficiency of singlet oxygen production, $\Phi_{\Delta}$, was estimated to be 0.70 and 0.60 for ( \pm -11 and $\mathbf{A}^{\mathbf{2}}$, respectively, by comparison with phenalenone as the reference compound, all measurements being performed in the same solvent (Table 1 and Figure S6). ${ }^{54}$ The observed $\Phi_{\Delta}$ values are quite remarkable, indicating that the coumarin-fused pCp derivatives can be considered as efficient heavy atom free sensitizers for singlet oxygen generation opening the way for photodynamic therapy applications. ${ }^{55}$
The very different photophysical properties observed for the two series of compounds are the signature of profound modifications of the excited electronic structures and motivated us to undertake a complete theoretical study by TD-DFT (CAM-B3LYP/6-311+G(d,p) level). All computational details are given in supplementary information while the main results are highlighted below. Focusing on the lowest energy transition $\left(\mathrm{S}_{1}-\mathrm{S}_{0}\right)$, a clear identifiable CT character is observed in the case of ( \pm )-5 and the related antenna $\mathbf{A}^{\mathbf{1}}$ (Figure 5) as characterized by the large computed $\mathrm{D}_{\mathrm{CT}}$ and $\mathrm{Q}_{\mathrm{CT}}$ values. ${ }^{56-57}$ For both molecules, this CT happens between the two phenyl rings of paracyclophane. These results agree with the large Stokes shift measured for $\mathbf{A}^{\mathbf{1}}$, that can be easily explained by the electronwithdrawing character of the picolinate motif. On the other hand, the nature of the $S_{1}-S_{0}$ transition for ( \pm )-11 and $\mathbf{A}^{\mathbf{2}}$ seems to be localized on one side of the paracyclophane, also in agreement with the experimental data where no solvatochromism was observed. To further investigate the feasibility of the singlet oxygen sensitization of the four molecules, the spin-orbit coupling (SOC) between the $S_{1}$ and lowest triplet states was computed at the TD-DFT level using the Douglas-Kroll Hamiltonian with the Dalton code (see specifications in supplementary information). The electron variation density of these transitions was also computed and is presented in Figures S7 and S8. While for the molecules substituted with an ether function, the SOC for $S_{1}-T_{1}$ is relatively low $\left(<0.5 \mathrm{~cm}^{-1}\right)$, this value is greatly increased in the case of the coumarin based molecules, with coupling intensities higher than $1 \mathrm{~cm}^{-1}$ for $( \pm)-\mathbf{1 1}$ and $\mathbf{A}^{\mathbf{2}}$, respectively. The computed lowest triplet state energies as well as the SOC calculated from the $S_{1}$ state are summarized in Figure 6 . 

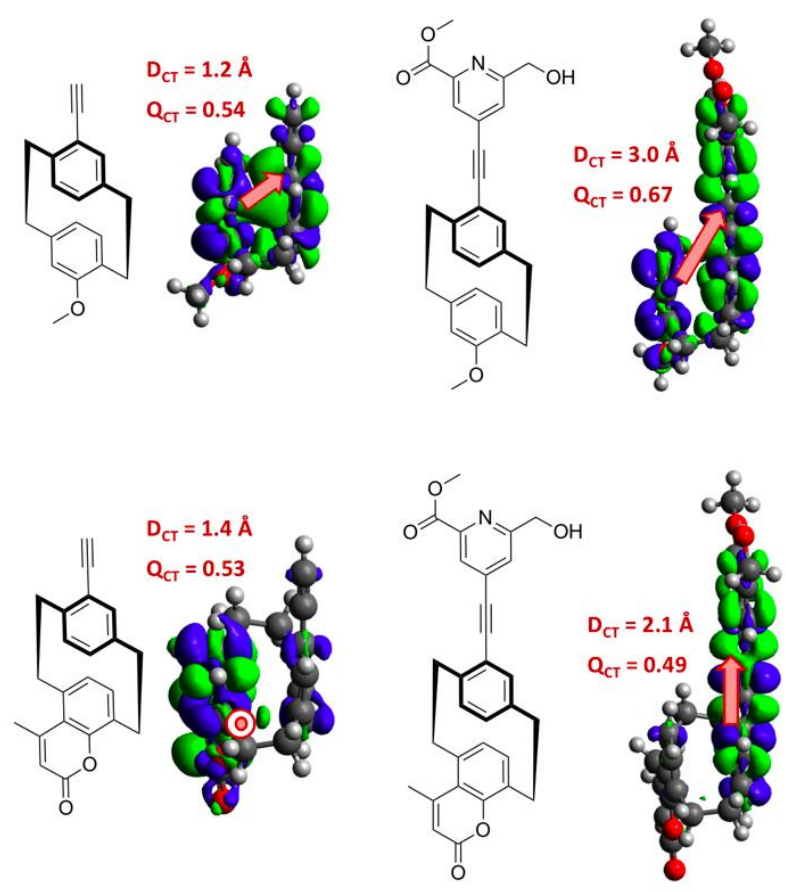

Figure 1. Computed electron variation density associated to the $\mathrm{S}_{0}-\mathrm{S}_{1}$ transition (blue and green correspond to the electron density decrease and increase respectively, isovalue 0.001 a.u.). Red arrows correspond to the $\mathrm{D}_{\mathrm{CT}}$ vectors.
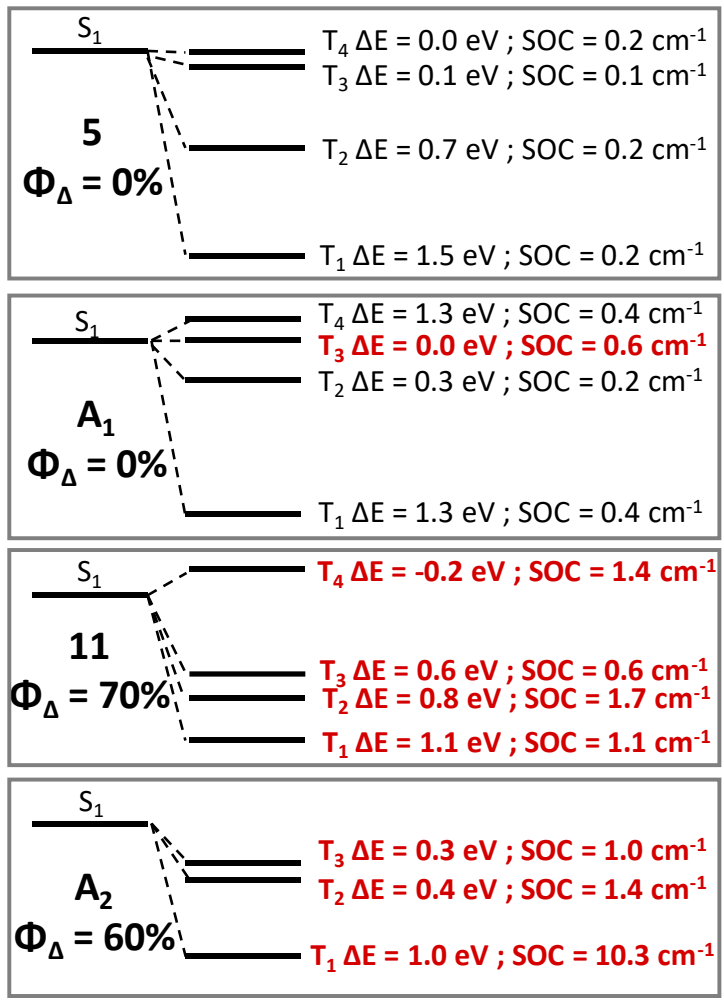

Figure 6. Computed Spin-orbit Coupling for the $\left(S_{1}, T_{1}\right),\left(S_{1}\right.$, $\left.\mathrm{T}_{2}\right),\left(\mathrm{S}_{1}, \mathrm{~T}_{2}\right)$ and $\left(\mathrm{S}_{1}, \mathrm{~T}_{4}\right)$ states along with their energy differences and the experimental value of singlet oxygen generation efficiency. In red, SOCs larger than $0.5 \mathrm{~cm}^{-1}$.
In general terms, the computed variation of SOC of the two families of compounds perfectly matches the experimental results on the singlet oxygen generation, where no singlet oxygen was observed in the case of the -OHex derivatives but relatively high efficiencies $(>60 \%)$ were found in the case of the coumarin-based compounds.

Photophysical characterization of the lanthanide complexes. The previous sections highlighted how the nature of the excited states of the paracyclophane antennas can be modulated by selection of the right substituents. Consequently, the sensitization mechanism of the lanthanide ion is expected to be strongly affected by this nature. $\mathbf{A}^{\mathbf{1}}$ presents a strong throughspace CT character together with a weak ISC ability and both energy levels $\left(\mathrm{E}(\mathrm{CT})^{*}=20100 \mathrm{~cm}^{-1}\right.$ and $\left.\mathrm{E}\left(\mathrm{T}^{1}\right)=20000 \mathrm{~cm}^{-1}\right)$ seem to be appropriate for $\mathrm{Eu}$ (III) sensitization $\left(\mathrm{Eu}^{3+}\right.$ accepting levels: $\operatorname{Eu}\left({ }^{5} D_{1}\right)=19,000 \mathrm{~cm}^{-1}$ and $\operatorname{Eu}\left({ }^{5} D_{0}\right)=17,200 \mathrm{~cm}^{-1}$, respectively). The room temperature and $77 \mathrm{~K}$ spectra of $\mathrm{EuL}^{1}$ are reported in Figure 7.

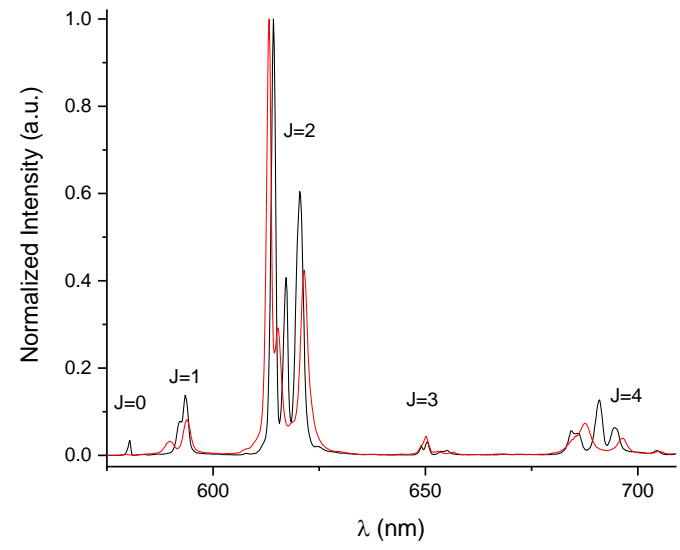

Figure 7. Normalized emission $\left(\lambda_{\text {exc }}=325 \mathrm{~nm}\right)$ spectra of EuL $\mathbf{L}^{\mathbf{1}}$ in dichloromethane at room temperature (red trace) and $77 \mathrm{~K}$ (black trace). The nature of the ${ }^{5} \mathrm{D}_{0} \rightarrow{ }^{7} \mathrm{~F}_{\mathrm{J}}$ transition are indicated.

The characteristic emission profile of the $\mathrm{Eu}(\mathrm{III}){ }^{5} \mathrm{D}_{0} \rightarrow{ }^{7} \mathrm{~F}_{\mathrm{J}}$ transitions is observed. Interestingly, no residual ligand centered emission at higher energy is present which indicates a very efficient energy transfer from the antenna to the excited states of europium. The relative intensity of the different ${ }^{5} \mathrm{D}_{0} \rightarrow{ }^{7} \mathrm{~F}_{\mathrm{J}}(\mathrm{J}=0$ to 4$)$ transitions is $0.05,1,10.3,0.5,1.8$ at $\mathrm{RT}$ using the magnetic dipole transition $\mathrm{J}=1$ as internal standard. This distribution is sensitive to ligand field splitting (LFS) and a qualitative indicator of the complex symmetry in solution. ${ }^{58}$ The hypersensitive $\mathrm{J}=2$ transition is the most intense and concentrates $\mathrm{R}^{2}=75.2 \%$ of the total intensity and the ratio between the intensity of the $\mathrm{J}=2$ over the $\mathrm{J}=4$ transitions $\mathrm{r}=5.7$. These values are close to that obtained for other related $C_{3}$ symmetric TACN complexes $\left(\mathrm{R}^{2}=79 \%, \mathrm{r}=10.9\right)$ but the more intense $\mathrm{J}=4$ transition suggests a slight distortion from this threefold symmetry. ${ }^{59}$ At low temperature the spectra is better resolved, giving more indications about the complex symmetry (Figure 7). Here, the fine splitting of the bands ( 2 for $\mathrm{J}=1$, and 3 for $\mathrm{J}=2$ ) suggests a high symmetry around the $\mathrm{Eu}(\mathrm{III})$ ion, typically $D_{3 h}$ symmetry expected for TACN-trispicolinate 
derivatives. ${ }^{60}$ The overall quantum yield at room temperature was found to be of 0.33 with a mono-exponential lifetime decay of $0.93 \mathrm{~ms}$ at $612 \mathrm{~nm}$ (Figures S9 and S10). Both values indicate a generally good sensitization of the central $\mathrm{Eu}^{3+}$ ion, highlighting the use of $\mathbf{A}^{\mathbf{1}}$ paracyclophane derivatives as efficient antennas.

Table 2. Main photophysical properties of the lanthanide complexes in diluted dichloromethane solutions at room temperature and $77 \mathrm{~K}$ (glass).

\begin{tabular}{ccccccc}
\hline & $\lambda_{\text {abs }}$ & $\varepsilon$ & $\lambda_{\text {em }}$ & $\tau_{\text {obs }}$ & $\Phi^{\mathrm{a}}$ & $\Phi_{\Delta}{ }^{\mathrm{b}}$ \\
& $\mathrm{nm}$ & ${\mathrm{L} \cdot \mathrm{mol}^{-1} \cdot \mathrm{cm}^{-1}}_{\mathrm{nm}}$ & $\mu \mathrm{s}$ & & \\
\hline $\mathrm{EuL}^{1}$ & 325 & 44000 & 612 & 930 & 0.33 & - \\
$\mathrm{YbL}^{2}$ & 339 & 48500 & 980 & 9.48 & $<0.01$ & 0.00 \\
$\mathrm{GdL}^{2}$ & 339 & 61000 & 422 & - & $<0.01$ & 0.45
\end{tabular}

a. Measured by comparative method using quinine sulfate $(0.54$ in $\left.\mathrm{H}_{2} \mathrm{SO}_{4} 0.5 \mathrm{M}\right)$ as standard. b. Measured by comparative method using phenalenone as standard $\left(\Phi_{\Delta}=0.98\right.$ in dichloromethane). ${ }^{54}$

On the other hand, the $\mathbf{A}^{\mathbf{2}}$ antenna was found to present a localized excited state with a strong intersystem-crossing efficiently populating the triplet sate localized at $19500 \mathrm{~cm}^{-1}$ that acts as a very good sensitizer for singlet oxygen generation $\left(\phi_{\Delta}=0.60\right)$. Therefore, the $\mathrm{Gd} \mathbf{L}^{2}$ complex was synthetized and its photophysical properties studied (Figure 8). As for the $\mathbf{A}^{\mathbf{2}}$ antenna, an intense phosphorescence band was observed at low temperature confirming the efficient ISC process in the complex. The generation of singlet oxygen was also observed with a quantum yield of 0.45 , slightly lower than the $\mathbf{A}^{2}$ antenna (Figure S11). This value is in the range of that observed in the literature. ${ }^{61-68}$

We also studied the related $\mathrm{Yb}(\mathrm{III})$ complex, $\mathrm{YbL}^{2}$ in dichloromethane and $\mathrm{MeOH}-\mathrm{EtOH}$ mixture (Figure 9). As already described in the literature, ${ }^{23,65}$ no singlet oxygen is observed but the clear signature of $\mathrm{Yb}$ (III) ${ }^{7} \mathrm{~F}_{5 / 2} \rightarrow{ }^{7} \mathrm{~F}_{7 / 2}$ transition in the NIR (980-1100 nm) is detected (Figure 9). At room temperature in dichloromethane, the lifetime decay measured at $980 \mathrm{~nm}$ was mono-exponentially fitted with a value of $9.48 \mu \mathrm{s}$, which indicates the presence of single species in solution (Figure S12). At low temperature, the spectrum remains poorly resolved with the presence of remaining "hot bands" at $973 \mathrm{~nm}$. The total ligand field splitting (LFS ${ }^{\text {max }}$ ) can be estimated to ca. $400 \mathrm{~cm}^{-1}$, close to that of threefold symmetry complexes reported in the literature $\left(\mathrm{LFS}^{\max }\right.$ in the range $\left.340-370 \mathrm{~cm}^{-1}\right){ }^{34}$ 59, 69-71 The slightly higher value confirms the distortion from the threefold symmetry already mentioned for $\operatorname{EuL}^{\mathbf{1}}$. The absence of singlet oxygen emission at $1270 \mathrm{~nm}$ further indicates a preferable intramolecular energy transfer from the triplet of the ligand to the ${ }^{7} \mathrm{~F}_{5 / 2}$ of the central $\mathrm{Yb}^{3+}$ ion above an intermolecular energy transfer to the molecule of $\mathrm{O}_{2}{ }^{23,65}$

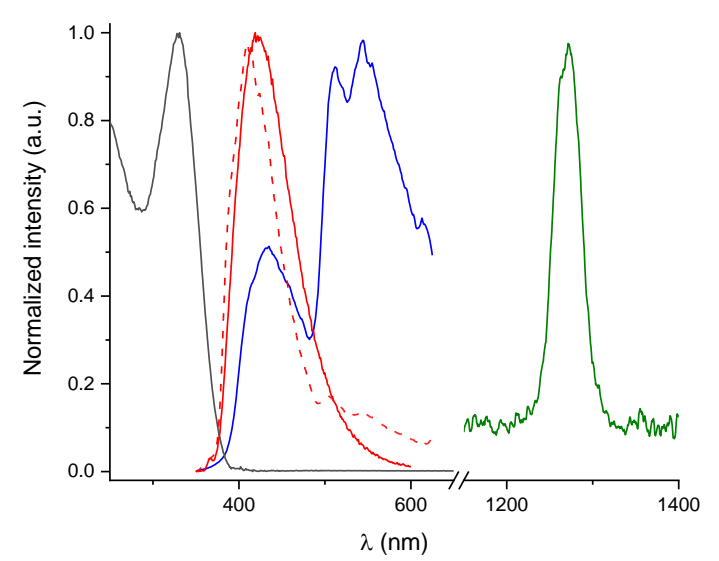

Figure 8. Normalized absorption (black), emission $\left(\lambda_{\text {exc }}=325\right.$ $\mathrm{nm})$ spectra for $\mathrm{Gd}^{2}$ in dichloromethane at room temperature (red trace), $77 \mathrm{~K}$ (dashed red) and after application of a $0.1 \mathrm{~ms}$ delay (blue). The green spectrum in the NIR is representative for the singlet oxygen luminescence.

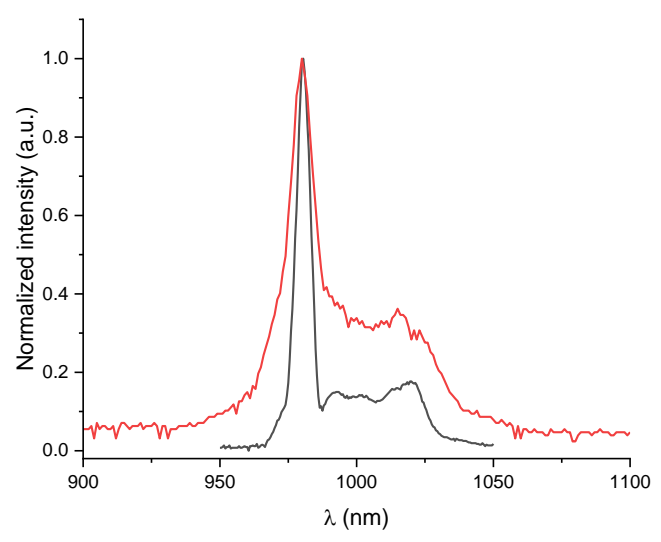

Figure 2. Normalized emission $\left(\lambda_{\text {exc }}=325 \mathrm{~nm}\right)$ spectra for $\mathrm{YbL}^{2}$ in $\mathrm{MeOH}-\mathrm{EtOH}(1-4 \mathrm{vol})$ at room temperature (red trace) and $77 \mathrm{~K}$ (black trace).

\section{Conclusion.}

In this article we described the multi-step synthesis of original antennas incorporating substituted paracylophane moieties in the $\pi$-conjugated skeleton. Two kinds of antennas have been investigated, incorporating either an alkoxy donor group or a fused coumarin moiety. A combined photophysical/theoretical study reveals that when substituted with the electron donating alkoxy fragment, the $\mathrm{pCp}$ enables a through-space conjugation inducing a fully delocalized charge transfer transition, whereas in the case of the coumarin-fused pCp chromophore only local excited states are present, strongly favoring triplet state population via intersystem crossing. When grafted to TACN, the alkoxy substituted chromophore behaves as a CT antenna able to efficiently sensitized Eu(III) luminescence. In contrast the coumarin-fused pCp antenna is able to sensitized $\mathrm{Yb}$ (III) or 
to efficiently produced singlet oxygen when associated to a nonemissive $\mathrm{Gd}(\mathrm{III})$ ion. This work clearly emphasizes the versatility of $\mathrm{pCp}$-based chromophores whose behavior can be finely tuned by chemical modification. This versatility can be exploited as a new toolbox for the design of lanthanides complexes with variable photophysical properties.

\section{Acknowledgements.}

Authors acknowledge the, Agence Nationale de la Recherche (ANR SMMCPL-13-BS07-0007-01) for a grant to LAG. Authors also gratefully thank the CNRS, Université de Paris (ANR-18-IDEX-0001) and the Ministère de l'Enseignement Supérieur et de la Recherche for financial support. Chinese Scholarship Council is acknowledged for a grant to SW. BLG the French GENCI/IDRIS-CINES center for high performance computing resources.

Keywords. Lanthanide complexes $\bullet$ paracyclophane $\bullet$ charge transfer $\bullet$ singlet oxygen

\section{References.}

1. Bünzli, J.-C. G.; Eliseeva, S. V., Intriguing aspects of lanthanide luminescence. Chem. Sci. 2013, 4, 1939-1949.

2. Bünzli, J.-C. G., On the design of highly luminescent lanthanide complexes. Coord. Chem. Rev. 2015, 293-294, 19-47.

3. Jüstel, T.; Nikol, H.; Ronda, C., New Developments in the Field of Luminescent Materials for Lighting and Displays. Angew. Chem. Int. Ed. 1998, 37, 3084-3103.

4. Guillou, O.; Daiguebonne, C.; Calvez, G.; Bernot, K., A Long Journey in Lanthanide Chemistry: From Fundamental Crystallogenesis Studies to Commercial Anticounterfeiting Taggants. Acc. Chem. Res. 2016, 49, 844-856.

5. Bünzli, J.-C. G., Lanthanide Luminescence for Biomedical Analyses and Imaging. Chem. Rev. 2010, 110, 27292755.

6. New, E. J.; Parker, D.; Smith, D. G.; Walton, J. W., Development of responsive lanthanide probes for cellular applications. Curr. Opin. Chem. Biol. 2010, 14, 238-46.

7. Heffern, M. C.; Matosziuk, L. M.; Meade, T. J., Lanthanide probes for bioresponsive imaging. Chem. Rev. 2014, $114,4496-539$.

$8 . \quad$ Jin, G.-Q.; Ning, Y.; Geng, J.-X.; Jiang, Z.-F.; Wang, Y.; Zhang, J.-L., Joining the journey to near infrared (NIR) imaging: the emerging role of lanthanides in the designing of molecular probes. Inor. Chem. Front. 2020, 7, 289-299.

9. Sy, M.; Nonat, A.; Hildebrandt, N.; Charbonniere, L. J., Lanthanide-based luminescence biolabelling. Chem Commun 2016, 52, 5080-95.

10. Zwier, J. M.; Bazin, H.; Lamarque, L.; Mathis, G., Luminescent lanthanide cryptates: from the bench to the bedside. Inorg. Chem. 2014, 53, 1854-66.

11. Zhang, K. Y.; Yu, Q.; Wei, H.; Liu, S.; Zhao, Q.; Huang, W., Long-Lived Emissive Probes for Time-Resolved Photoluminescence Bioimaging and Biosensing. Chem. Rev. 2018, 118, 1770-1839.

12. Pointillart, F.; le Guennic, B.; Cador, O.; Maury, O.; Ouahab, L., Lanthanide ion and tetrathiafulvalene-based ligand as a "magic" couple toward luminescence, single molecule magnets, and magnetostructural correlations. Acc. Chem. Res. 2015, 48, 2834-42.
13. Marin, R.; Brunet, G.; Murugesu, M., Shining new light on multifunctional lanthanide single-molecule magnets. Angew. Chem. Int. Ed. Engl. 2021, 60, 1728.

14. Parker, D.; Suturina, E. A.; Kuprov, I.; Chilton, N. F., How the Ligand Field in Lanthanide Coordination Complexes Determines Magnetic Susceptibility Anisotropy, Paramagnetic NMR Shift, and Relaxation Behavior. Acc. Chem. Res. 2020, 53, 1520-1534.

15. Weissman, S. I., Intramolecular Energy Transfer The Fluorescence of Complexes of Europium. J. Chem. Phys. 1942, 10, 214-217.

16. Sabbatini, N.; Guardigli, M.; Lehn, J.-M., Luminescent lanthanide complexes as photochemical supramolecular devices. Coord. Chem. Rev. 1993, 123, 201-228.

17. D'Aléo, A.; Pointillart, F.; Ouahab, L.; Andraud, C.; Maury, O., Charge transfer excited states sensitization of lanthanide emitting from the visible to the near-infra-red. Coord. Chem. Rev. 2012, 256, 1604-1620.

18. Walton, J. W.; Bourdolle, A.; Butler, S. J.; Soulie, M.; Delbianco, M.; McMahon, B. K.; Pal, R.; Puschmann, H.; Zwier, J. M.; Lamarque, L.; Maury, O.; Andraud, C.; Parker, D., Very bright europium complexes that stain cellular mitochondria. Chem Commun. 2013, 49, 1600-2.

19. Xu, J.; Corneillie, T. M.; Moore, E. G.; Law, G.-L.; Butlin, N. G.; Raymond, K. N., Octadentate Cages of Tb(III) 2Hydroxyisophthalamides: A New Standard for Luminescent Lanthanide Labels. J. Am. Chem. Soc. 2011, 133, 19900-19910.

20. Moore, E. G.; Samuel, A. P. S.; Raymond, K. N., From Antenna to Assay: Lessons Learned in Lanthanide Luminescence. Acc. Chem. Res. 2009, 42, 542-552.

21. Hu, J. Y.; Ning, Y.; Meng, Y. S.; Zhang, J.; Wu, Z. Y.; Gao, S.; Zhang, J. L., Highly near-IR emissive ytterbium(iii) complexes with unprecedented quantum yields. Chem Sci 2017, 8, 2702-2709.

22. Ward, M. D., Mechanisms of sensitization of lanthanide(III)-based luminescence in transition metal/lanthanide and anthracene/lanthanide dyads. Coord. Chem. Rev. 2010, 254, 2634-2642.

23. Watkis, A.; Hueting, R.; Sorensen, T. J.; Tropiano, M.; Faulkner, S., Controlling energy transfer in ytterbium complexes: oxygen dependent lanthanide luminescence and singlet oxygen formation. Chem Commun 2015, 51, 15633-6.

24. New, E. J.; Congreve, A.; Parker, D., Definition of the uptake mechanism and sub-cellular localisation profile of emissive lanthanide complexes as cellular optical probes. Chem. Sci. 2010, 1, 111-118.

25. Pershagen, E.; Borbas, K. E., Multiplex detection of enzymatic activity with responsive lanthanide-based luminescent probes. Angew. Chem. Int. Ed. Engl. 2015, 54, 1787-90.

26. Junker, A. K. R.; Hill, L. R.; Thompson, A. L.; Faulkner, S.; Sorensen, T. J., Shining light on the antenna chromophore in lanthanide based dyes. Dalton Trans 2018, 47, 4794-4803.

27. H. V. Werts, M.; A. Duin, M.; W. Hofstraat, J.; W. Verhoeven, J., Bathochromicity of Michler's ketone upon coordination with lanthanide(III) $\beta$-diketonates enables efficient sensitisation of $\mathrm{Eu}^{3+}$ for luminescence under visible light excitation†. Chem. Commun. 1999, 799-800.

28. Pointillart, F.; Jung, J.; Berraud-Pache, R.; Le Guennic, B.; Dorcet, V.; Golhen, S.; Cador, O.; Maury, O.; Guyot, Y.; Decurtins, S.; Liu, S. X.; Ouahab, L., Luminescence and singlemolecule magnet behavior in lanthanide complexes involving a tetrathiafulvalene-fused dipyridophenazine ligand. Inorg. Chem. 2015, 54, 5384-97. 
29. Yang, C.; Fu, L. M.; Wang, Y.; Zhang, J. P.; Wong, W. T.; Ai, X. C.; Qiao, Y. F.; Zou, B. S.; Gui, L. L., A highly luminescent europium complex showing visible-light-sensitized red emission: direct observation of the singlet pathway. Angew. Chem. Int. Ed. Engl. 2004, 43, 5010-3.

30. Hamon, N.; Roux, A.; Beyler, M.; Mulatier, J. C.; Andraud, C.; Nguyen, C.; Maynadier, M.; Bettache, N.; Duperray, A.; Grichine, A.; Brasselet, S.; Gary-Bobo, M.; Maury, O.; Tripier, R., Pyclen-Based Ln(III) Complexes as Highly Luminescent Bioprobes for In Vitro and In Vivo One- and Two-Photon Bioimaging Applications. J. Am. Chem. Soc. 2020, 142, 1018410197.

31. Ward, M. D., Transition-metal sensitised near-infrared luminescence from lanthanides in $\mathrm{d}-\mathrm{f}$ heteronuclear arrays. Coord. Chem. Rev. 2007, 251, 1663-1677.

32. Di Piazza, E.; Norel, L.; Costuas, K.; Bourdolle, A.; Maury, O.; Rigaut, S., d-f heterobimetallic association between ytterbium and ruthenium carbon-rich complexes: redox commutation of near-IR luminescence. J. Am. Chem. Soc. 2011, 133, 6174-6.

33. Al Sabea, H.; Norel, L.; Galangau, O.; Hijazi, H.; Metivier, R.; Roisnel, T.; Maury, O.; Bucher, C.; Riobe, F.; Rigaut, S., Dual Light and Redox Control of NIR Luminescence with Complementary Photochromic and Organometallic Antennae. J. Am. Chem. Soc. 2019, 141, 20026-20030.

34. Yi, X.; Bernot, K.; Le Corre, V.; Calvez, G.; Pointillart, F.; Cador, O.; Le Guennic, B.; Jung, J.; Maury, O.; Placide, V.; Guyot, Y.; Roisnel, T.; Daiguebonne, C.; Guillou, O., Unraveling the crystal structure of lanthanide-murexide complexes: use of an ancient complexometry indicator as a near-infrared-emitting single-ion magnet. Chem. Eur. J. 2014, 20, 1569-76.

35. Norel, L.; Galangau, O.; Al Sabea, H.; Rigaut, S., Remote Control of Near Infrared Emission with Lanthanide Complexes. ChemPhotoChem 2021, 5, 393.

36. Zhong, Y.; Si, L.; He, H.; Sykes, A. G., BODIPY chromophores as efficient green light sensitizers for lanthanideinduced near-infrared emission. Dalton Trans 2011, 40, 11389-95. 37. He, H.; Si, L.; Zhong, Y.; Dubey, M., Iodized BODIPY as a long wavelength light sensitizer for the near-infrared emission of ytterbium(III) ion. Chem Commun 2012, 48, 1886-8.

38 Brown, C. J.; Farthing, A. C., Preparation and Structure of Di-p-Xylylene. Nature 1949, 164, 915-916.

39. Hope, H.; Bernstein, J.; Trueblood, K. N., The crystal and molecular structure of 1,1,2,2,9,9,10,10-octafluoro[2,2]paracyclophane and a reinvestigation of the structure of [2,2]paracyclophane. Acta Crystallogr. Section B 1972, 28, 1733 1743 .

40. Bartholomew, G. P.; Ledoux, I.; Mukamel, S.; Bazan, G. C.; Zyss, J., Three-Dimensional Nonlinear Optical Chromophores Based on Through-Space Delocalization. J. Am. Chem. Soc. 2002, 124, 13480-13485.

41. Bartholomew, G. P.; Rumi, M.; Pond, S. J. K.; Perry, J. W.; Tretiak, S.; Bazan, G. C., Two-Photon Absorption in ThreeDimensional Chromophores Based on [2.2]-Paracyclophane. $J$. Am. Chem. Soc. 2004, 126, 11529-11542.

42. Delcourt, M.-L.; Reynaud, C.; Turcaud, S.; Favereau, L.; Crassous, J.; Micouin, L.; Benedetti, E., 3D Coumarin Systems Based on [2.2]Paracyclophane: Synthesis, Spectroscopic Characterization, and Chiroptical Properties. J. Org. Chem. 2019, 84, 888-899.

43. Morisaki, Y.; Chujo, Y., Planar Chiral [2.2]Paracyclophanes: Optical Resolution and Transformation to Optically Active $\pi$-Stacked Molecules. Bull. Chem. Soc. Jpn. 2019, 92, 265-274.
44. Cram, D. J.; Allinger, N. L., Macro Rings. XII. Stereochemical Consequences of Steric Compression in the Smallest Paracyclophane1. J. Am. Chem. Soc. 1955, 77, 62896294.

45. Grykien, R.; Luszczynska, B.; Glowacki, I.; Puntus, L.; Pekareva, I.; Lyssenko, K.; Kajzar, F.; Rau, I.; Lazar, C. A., Electric field tunable light emitting diodes containing europium $\beta$ diketonates with [2.2] paracyclophane moiety. Opt. Mater. 2016, 57, 114-119.

46. D'Aléo, A.; Bourdolle, A.; Brustlein, S.; Fauquier, T.; Grichine, A.; Duperray, A.; Baldeck, P. L.; Andraud, C.; Brasselet, S.; Maury, O., Ytterbium-Based Bioprobes for Near-Infrared TwoPhoton Scanning Laser Microscopy Imaging. Angew. Chem. Int. Ed. 2012, 51, 6622-6625.

47. Soulie, M.; Latzko, F.; Bourrier, E.; Placide, V.; Butler, S. J.; Pal, R.; Walton, J. W.; Baldeck, P. L.; Le Guennic, B.; Andraud, C.; Zwier, J. M.; Lamarque, L.; Parker, D.; Maury, O., Comparative analysis of conjugated alkynyl chromophoretriazacyclononane ligands for sensitized emission of europium and terbium. Chem. Eur. J. 2014, 20 (28), 8636-46.

48. Bui, A. T.; Roux, A.; Grichine, A.; Duperray, A.; Andraud, C.; Maury, O., Twisted Charge-Transfer Antennae for Ultra-Bright Terbium(III) and Dysprosium(III) Bioprobes. Chem; Eur; J. 2018, 24, 3408-3412.

49. Kane, V. V.; Gerdes, A.; Grahn, W.; Ernst, L.; Dix, I.; Jones, P. G.; Hopf, H., A novel entry into a new class of cyclophane derivatives: synthesis of ( \pm )-[2.2]paracyclophane-4-thiol. Tetrahedron Lett. 2001, 42, 373-376.

50. Ma, Q.; Ma, Y.; Liu, X.; Duan, W.; Qu, B.; Song, C., Planar chiral imidazolium salts based on [2.2]paracyclophane in the asymmetric rhodium-catalyzed 1,2-addition of arylboronic acids to aldehydes. Tetrahedron: Asymmetry 2010, 21, 292-298.

51. Nurmukhametov, R. N.; Shapovalov, A. V.; Sergeev, A. M., Absorption and Luminescence Properties of [2.2]Paracyclophane due to Strong Transannular Interaction. $J$. Appl. Spectrosc. 2014, 81, 49-56.

52. Gallavardin, T.; Maurin, M.; Marotte, S.; Simon, T.; Gabudean, A. M.; Bretonniere, Y.; Lindgren, M.; Lerouge, F.; Baldeck, P. L.; Stephan, O.; Leverrier, Y.; Marvel, J.; Parola, S.; Maury, O.; Andraud, C., Photodynamic therapy and two-photon bio-imaging applications of hydrophobic chromophores through amphiphilic polymer delivery. Photochem Photobiol Sci 2011, 10, 1216-25.

53. D’Aléo, A.; Picot, A.; Beeby, A.; Gareth Williams, J. A.; Le Guennic, B.; Andraud, C.; Maury, O., Efficient Sensitization of Europium, Ytterbium, and Neodymium Functionalized TrisDipicolinate Lanthanide Complexes through Tunable ChargeTransfer Excited States. Inorg. Chem. 2008, 47, 10258-10268.

54. Schmidt, R.; Tanielian, C.; Dunsbach, R.; Wolff, C., Phenalenone, a universal reference compound for the determination of quantum yields of singlet oxygen $\mathrm{O} 2(1 \Delta \mathrm{g})$ sensitization. J. Photochem. Photobiol. A: Chem. 1994, 79, 11-17. 55. Nguyen, V. N.; Yan, Y.; Zhao, J.; Yoon, J., Heavy-AtomFree Photosensitizers: From Molecular Design to Applications in the Photodynamic Therapy of Cancer. Acc. Chem. Res. 2021, 54, 207-220.

56. Le Bahers, T.; Adamo, C.; Ciofini, I., A Qualitative Index of Spatial Extent in Charge-Transfer Excitations. J. Chem. Theo. Comput. 2011, 7, 2498-2506.

57. Adamo, C.; Le Bahers, T.; Savarese, M.; Wilbraham, L.; García, G.; Fukuda, R.; Ehara, M.; Rega, N.; Ciofini, I., Exploring excited states using Time Dependent Density Functional Theory and density-based indexes. Coord. Chem. Rev. 2015, 304-305, 166178. 
58. Tanner, P. A., Some misconceptions concerning the electronic spectra of tri-positive europium and cerium. Chem. Soc. Rev. 2013, 42, 5090-101.

59. Mendy, J.; Thy Bui, A.; Roux, A.; Mulatier, J. C.; Curton, D.; Duperray, A.; Grichine, A.; Guyot, Y.; Brasselet, S.; Riobe, F.; Andraud, C.; Le Guennic, B.; Patinec, V.; Tripier, P. R.; Beyler, M.; Maury, O., Cationic Biphotonic Lanthanide Luminescent Bioprobes Based on Functionalized Cross-Bridged Cyclam Macrocycles. Chemphyschem 2020, 21, 1036-1043.

60. Nocton, G.; Nonat, A.; Gateau, C.; Mazzanti, M., Water Stability and Luminescence of Lanthanide Complexes of Tripodal Ligands Derived from 1,4,7-Triazacyclononane: Pyridinecarboxamide versus Pyridinecarboxylate Donors. Helv. Chim. Acta 2009, 92, 2257-2273.

61. Law, G. L.; Pal, R.; Palsson, L. O.; Parker, D.; Wong, K. L., Responsive and reactive terbium complexes with an azaxanthone sensitiser and one naphthyl group: applications in ratiometric oxygen sensing in vitro and in regioselective cell killing. Chem Commun 2009, 7321-3.

62. Zhang, T.; Lan, R.; Chan, C. F.; Law, G. L.; Wong, W. K.; Wong, K. L., In vivo selective cancer-tracking gadolinium eradicator as new-generation photodynamic therapy agent. Proc Natl Acad Sci U S A 2014, 111, E5492-7.

63. Sorensen, T. J.; Kenwright, A. M.; Faulkner, S., Bimetallic lanthanide complexes that display a ratiometric response to oxygen concentrations. Chem. Sci. 2015, 6, 2054-2059.

64. Lo, W.-S.; Li, H.; Law, G.-L.; Wong, W.-T.; Wong, K.L., Efficient and selective singlet oxygen sensitized NIR luminescence of a neodymium(III) complex and its application in biological imaging. J. Lumin. 2016, 169, 549-552.

65. Galland, M.; Riobé, F.; Ouyang, J.; Saleh, N.; Pointillart, F.; Dorcet, V.; Le Guennic, B.; Cador, O.; Crassous, J.; Andraud, C.; Monnereau, C.; Maury, O., Helicenic Complexes of Lanthanides: Influence of the f-Element on the Intersystem Crossing Efficiency and Competition between Luminescence and Oxygen Sensitization. Eur. J. Inorg. Chem. 2019, 118-125.

66. Zhang, J. X.; Chan, W. L.; Xie, C.; Zhou, Y.; Chau, H. F.; Maity, P.; Harrison, G. T.; Amassian, A.; Mohammed, O. F.; Tanner, P. A.; Wong, W. K.; Wong, K. L., Impressive near-infrared brightness and singlet oxygen generation from strategic lanthanideporphyrin double-decker complexes in aqueous solution. Light Sci Appl 2019, 8, 46.

67. Galland, M.; Le Bahers, T.; Banyasz, A.; Lascoux, N.; Duperray, A.; Grichine, A.; Tripier, R.; Guyot, Y.; Maynadier, M.; Nguyen, C.; Gary-Bobo, M.; Andraud, C.; Monnereau, C.; Maury, O., A "Multi-Heavy-Atom" Approach toward Biphotonic Photosensitizers with Improved Singlet-Oxygen Generation Properties. Chem. Eur. J. 2019, 25, 9026-9034.

68. Johnson, K. R.; de Bettencourt-Dias, A., 102 Generating Luminescent Lanthanide Complexes with 1,8-NaphthalimideBased Sensitizers. Inorg. Chem. 2019, 58 (19), 13471-13480.

69. Reinhard, C.; Güdel, H. U., High-Resolution Optical Spectroscopy of $\mathrm{Na}_{3}\left[\mathrm{Ln}(\mathrm{dpa})_{3}\right] \cdot 13 \mathrm{H}_{2} \mathrm{O}$ with $\mathrm{Ln}=\mathrm{Er}^{3+}, \mathrm{Tm}^{3+}, \mathrm{Yb}^{3+}$. Inorg. Chem. 2002, 41, 1048-1055.

70. Gonçalves e Silva, F. R.; Malta, O. L.; Reinhard, C.; Güdel, H.-U.; Piguet, C.; Moser, J. E.; Bünzli, J.-C. G., Visible and Near-Infrared Luminescence of Lanthanide-Containing Dimetallic Triple-Stranded Helicates: Energy Transfer Mechanisms in the SmIII and YbIII Molecular Edifices. J. Phys. Chem. A 2002, 106, 1670-1677.

71. Gendron, F.; Di Pietro, S.; Abad Galán, L.; Riobé, F.; Placide, V.; Guy, L.; Zinna, F.; Di Bari, L.; Bensalah-Ledoux, A.; Guyot, Y.; Pilet, G.; Pointillart, F.; Baguenard, B.; Guy, S.; Cador, O.; Maury, O.; Le Guennic, B., Luminescence, chiroptical, magnetic and ab initio crystal-field characterizations of an enantiopure helicoidal Yb(III) complex. Inorg. Chem. Front. 2021, 8, 914-926. 